\title{
Correcting for Hubris in Project Appraisal
}

\author{
Jacques A. Schnabel \\ School of Business \& Economics, Wilfrid Laurier University, Waterloo, ON, Canada N2L 3C5 \\ Correspondence should be addressed to Jacques A. Schnabel, jschnabel@wlu.ca
}

Received 18 April 2012; Accepted 28 May 2012

Academic Editors: A. Rodriguez-Alvarez and B. M. Tabak

Copyright ( 12012 Jacques A. Schnabel. This is an open access article distributed under the Creative Commons Attribution License, which permits unrestricted use, distribution, and reproduction in any medium, provided the original work is properly cited.

Behavioral finance research stresses the prevalence of overconfidence in capital budgeting practices. To remedy this shortcoming, specifically the upward bias in cash flow forecasts, the extant literature emphasizes the reduction of such forecasts. This paper considers the conditions under which a different adjustment is warranted, namely, an upward correction in the hurdle rate employed to evaluate the project. It is argued here that if adverse events can have a long-term, versus a merely transitory, deleterious effect on the project's cash flows, the second adjustment is appropriate.

\section{Introduction}

A recurring theme in the behavioral literature on corporate finance is the endemic presence of hubris in the project appraisal process, that is, excessive optimism mars capital budgeting practices. As an antidote for the foregoing, numerous researchers have advanced procedures for correcting the cash flow projections associated with an investment proposal for this upward bias. This paper argues that, if adversity has a merely temporary effect on a project, a downward adjustment to the initial cash flow estimates suffices. However, if the adversity is of a more persistent nature, a second modification, namely, an upward revision of the discount rate, is apposite.

The next section reviews the literature on managerial overconfidence in capital budgeting and develops a simple paradigm, labelled here "an adversity sensitized NPV" (Net Present Value), for evaluating the adequacy of existing bias correction procedures. The succeeding two sections consider distinct scenarios where adverse events threaten the success of an investment undertaking. On the one hand, an unfavorable event may be merely transitory, affecting the cash flow of the project for solely one year, that is the year of the event's occurrence. On the other hand, the event may inflict permanent harm to the project affecting all the proposal's cash flows subsequent to the event's occurrence. In the former case, a reduction in the initial cash flow forecasts is adequate. However, in the latter case, the requisite adjustment is different, namely, an increase in the hurdle rate to reflect the probability of the adversity.

\section{Hubris in Project Evaluation}

A leitmotif in behavioral investigations of capital budgeting practices is the notion that such decisions are biased by overconfidence and excessive optimism. This notion occupies a central place in various treatments of the topic, be it in the popular press, as exemplified by Lovello and Kahneman [1], or in behavioral finance textbooks such as Shefrin [2] and Ackert and Deaves [3]. Disparate investigations have buttressed this view, for example, the empirical studies of Malmendier and Tate [4], Heaton [5], and Ben-David et al. $[6,7]$ and the experimental research of Statman and Tyebjee [8] and Camerer and Lovallo [9].

Numerous psychological sources for this hubristic tendency have been advanced, for example, use of the affect heuristic by which decisions are made emotionally, misperception of lower investment risk due to putative control of the project, the conjunction fallacy that results in a down bias in the assessed probability of adverse events, and wishful thinking whereby desirable outcomes are deemed more probable precisely because of their desirability.

To correct for the bias induced by managerial hubris, extant literature has emphasized tweaking cash flow forecasts. For example, Kahneman and Tversky [10] develop a statistical procedure to guide the requisite adjustments 
in cash flow. With a view to determining whether such adjustments suffice and whether fine-tuning the discount rate is warranted, this paper analyses a simple annuity-type investment proposal both before and after the excessive managerial optimism has been exorcised from the investment appraisal process.

Consider an investment proposal that will generate a series of equal cash flows at the end of each year for $N$ years. Bias in forecasting the initial investment is not considered here; solely the upward bias in the cash flows subsequent to the initial investment is entertained. Thus, the focus of this paper is on the present value of the subsequent cash flows or, more succinctly, PVSCF. The hurdle rate employed in the determination of PVSCF is denoted by $k$.

Given the foregoing, PVSCF is determined by the following well-known equation:

$$
\operatorname{PVSCF}=C\left[\frac{1}{(1+k)^{1}}+\cdots+\frac{1}{(1+k)^{N}}\right]
$$

Equation (1) may be represented in a more parsimonious fashion using the present value interest factor of an annuity for $N$ periods assuming a discount rate of $k$ or $\operatorname{PVIFA}(k, N)$, which equals the bracketed term in the same equation.

Consistent with the literature cited above, the cash flow forecast of $C$ per year reflects managerial overconfidence. In particular, $C$ does not reflect the possibility of an adverse event negatively impacting the project, resulting in a downward revision of the cash flow to a reduced level denoted $A$. The probability of the adverse event occurring is denoted by $p$. This paper addresses the question: how must PVSCF be revised to reflect the possibility of the adverse event and the attendant negative effect on the project's cash flows.

Two different assumptions are made regarding the cash flow impact of the adverse event. In the next section, the event is assumed to have a merely temporary effect, affecting solely the cash flow for the year in question, that is, cash flows in subsequent years will not necessarily equal $A$ but will be exposed to the same probability $p$ of the hostile event. In the section that follows, the adverse event is assumed to have a permanent effect on the investment proposal, reducing the cash flow for the year as well as all subsequent cash flows to the lower level $A$.

\section{Transitory Adversity}

As foreshadowed above, this section considers a situation where the occurrence of the adverse event, which has a probability of $p$, diminishes solely the cash flow for the year of the event to the reduced level of $A$ from the original forecast of $C$. In all subsequent years, the firm is exposed to the same probability that the cash flow will fall to $A$. Figure 1 presents a graphical depiction of the situation envisioned here for the specific case of a two-period project. The diagrammatic extension to a general $N$-period investment proposal is straightforward.
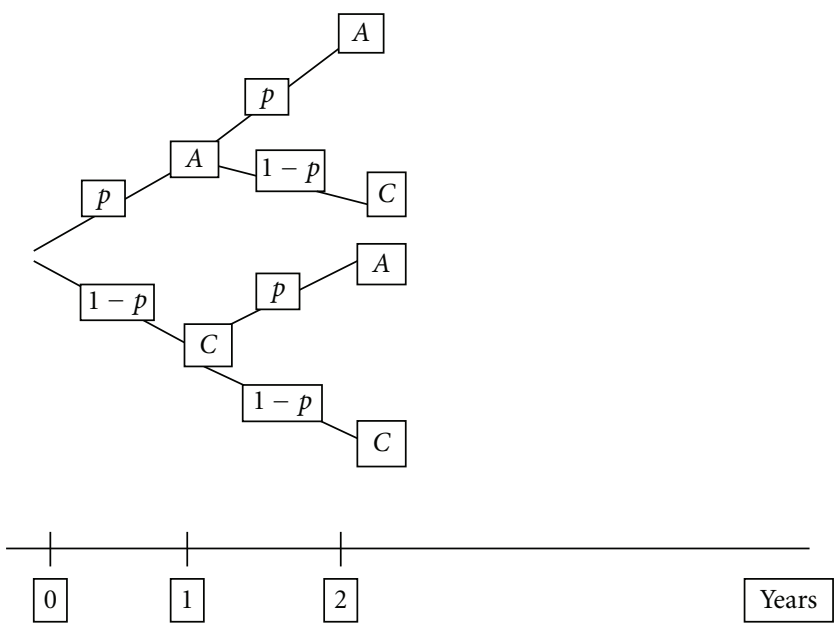

FIGURE 1: Depiction of transitory adversity for a two-period project.

Define $E_{t}$ as the revised cash flow forecast for year $t$, where adjustment is made for the possibility of the adverse event occurring. For the first year, the following holds:

$$
E_{1}=p A+(1-p) C .
$$

The analogous revised cash flow forecast for the second year is as follows:

$$
\begin{aligned}
E_{2} & =p[p A+(1-p) C]+(1-p)[p A+(1-p) C] \\
& =p A+(1-p) C .
\end{aligned}
$$

Thus, the following is obtained for any year $t$ :

$$
E_{t}=p A+(1-p) C=A+(1-p)(C-A) .
$$

The latter part of (4) articulates the revised cash flow forecast for a generic year $t$ as the reduced cash flow should the adversity eventuate plus the cash flow premium that results if adversity does not occur weighted by the corresponding probability. Stated another way, the cash flow generated under hostile conditions provides the base case or starting point to which incremental cash flow components are added should the adverse event fail to eventuate. Substituting the revised cash flow given by (4) in lieu of the original hubristic forecast of $C$ to (1) results in the following revised PVSCF formula that is obtained in the current scenario of transitory adversity:

$$
\operatorname{PVSCF}=[A+(1-p)(C-A)] \operatorname{PVIFA}(k, N) .
$$

Equation (5) confirms, that when unfavorable events have merely a temporary effect on the project, a downward revision of the original cash flow forecast suffices, that is, the hurdle rate remains equal to its original value of $k$.

\section{Persistent Adversity}

In contrast to the previous section, this part assumes that the occurrence of the adverse event during a certain year 

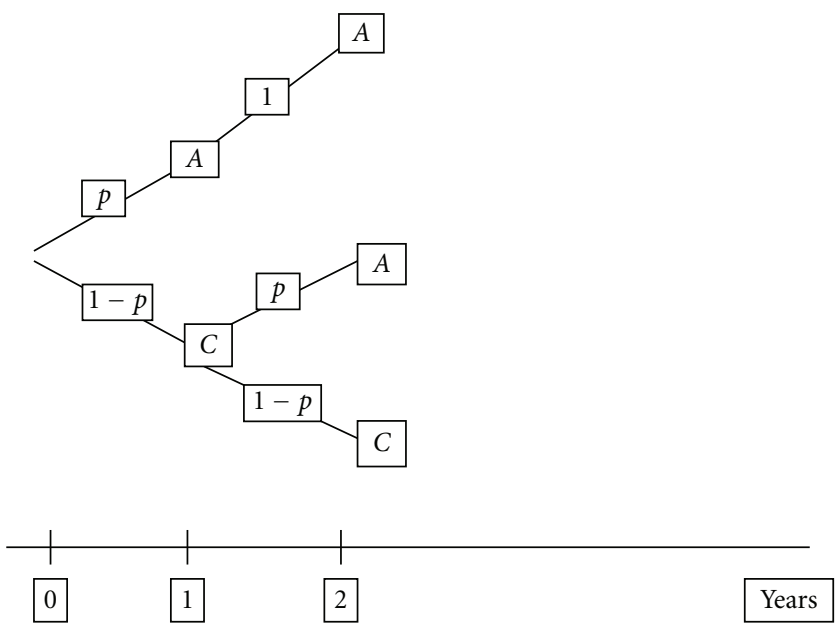

FIGURE 2: Depiction of persistent adversity for a two-period project.

reduces that year's cash flow as well as the cash flows of all subsequent years to the reduced level of $A$. Once the project encounters adversity, the project remains permanently in that undesirable state for the remaining life of the project. Invoking the statistical jargon of Markov Chains, adversity is viewed here as an absorbing state, that is, once the project enters a state of adversity it remains trapped in that state for the remaining life of the project. Figure 2 provides a graphical depiction of the envisaged random process for the specific case of a two-period project. The diagrammatic extension to a general $\mathrm{N}$-period investment proposal is straightforward.

Consider next the cash flow forecasts revised for the possibility of the unfavorable events. Clearly the first year's revised cash flow will also be given by (2). In contrast, the revised cash flow for year 2 is as follows:

$$
\begin{aligned}
E_{2} & =p A+(1-p)[p A+(1-p C)] \\
& =\left[1-(1-p)^{2}\right] A+(1-p)^{2} C .
\end{aligned}
$$

The preceding logic may be applied seriatim to the succeeding years, resulting in the following revised cash flow forecast for a generic year $t$ :

$$
E_{t}=\left[1-(1-p)^{t}\right] A+(1-p)^{t} C
$$

Substituting the revised cash flow forecast given by (7) in lieu of $C$ in (1) and algebraically simplifying result in the following revision of PVSCF that is purged of excessive optimism in the current scenario of persistent adversity:

$$
\begin{aligned}
\operatorname{PVSCF}= & A\left[\frac{1}{(1+k)^{1}}+\cdots+\frac{1}{(1+k)^{N}}\right] \\
& +(C-A)\left[\left(\frac{1-p}{1+k}\right)^{1}+\cdots+\left(\frac{1-p}{1+k}\right)^{N}\right] .
\end{aligned}
$$

Defining $R$ in the following manner:

$$
R=\frac{1+k}{1-p}-1
$$

Equation (8) may be reexpressed as

$$
\operatorname{PVSCF}=[A] \operatorname{PVIFA}(k, N)+[C-A] \operatorname{PVIFA}(R, N) .
$$

It is noteworthy that in (8) two discount rates are applied, namely the original rate of $k$ that applies to the reduced cash flow when adversity strikes, or the base case cash flow, and a second rate of $R$ that applies to the cash flow premium the project would enjoy in the absence of the adverse event. The new discount rate of $R$, which may be termed the adversity adjusted hurdle rate, is given by formula (9). Consistent with intuition, $R$ rises with the probability of the adverse event.

Equations (9) and (10) elucidate the proper dual adjustments to the original NPV calculations to purge the latter of hubris. Cash flow forecasts must be reduced and, for the cash flow component that exceeds the adversity level of $A$, a higher discount rate that reflects the probability of the unfavorable event occurring is applied.

\section{Numerical Example}

This penultimate section of the paper presents a numerical illustration of the adversity-sensitized NPV paradigm developed here with a view to demonstrating its utility. Consider an investment proposal whose duration is 10 years, with a hurdle rate or cost of capital of $15 \%$ and with a hubristic expected annual cash flow of $\$ 1,000$. Invoking (1), the hubris-tainted PVSCF of the proposal equals $\$ 5,019$, which is calculated as $\$ 1,000[\operatorname{PVIFA}(15 \%, 10)]$.

If the possibility of transitory adversity is introduced into the analysis, the hubris-corrected PVSCF given by formula (5) may be invoked, resulting in a revised PVSCF of $\$ 4,718$, which is calculated as $[\$ 400+(1-.1)(\$ 1000-$ $\$ 400)][\operatorname{PVIFA}(15 \%, 10)]$. In the foregoing, the annual probability of the transitory adverse event equals $10 \%$ and the reduced annual cash flow attained under this eventuality equals $\$ 400$.

However, if the possibility of permanent adversity, that likewise has an annual probability of $10 \%$, is introduced into the analysis, the corresponding hubris-corrected PVSCF given by formula (10) may be invoked. This results in a revised PVSCF of $\$ 3,969$, which is calculated as $\$ 400$ $[\operatorname{PVIFA}(15 \%, 10)]+(\$ 1000-\$ 400)[\operatorname{PVIFA}(28 \%, 10)]$. It is noteworthy that, in the foregoing calculation, correcting for hubris requires an upward-revised hurdle rate of $28 \%$, as given by formula (9), that is, $R=(1.15 / .9)-1$, and that this upward-revised hurdle rate applies to the cash flow forecast that exceeds the adversity level of $\$ 400$.

\section{Conclusion}

Employing simple present value mathematics, this paper has argued that the requisite adjustments to NPV necessitated by 
overconfidence and excessive optimism come in two forms if hostile events can have a permanent effect of the capital budgeting proposal. These are a downward revision of the original cash flow forecasts and an upward adjustment to the hurdle rate applied to the cash flow components that exceed the level generated under adverse conditions. Only if the deleterious effects of the hostile events are merely temporary can a financial analyst dispense with the hurdle rate adjustment.

\section{References}

[1] D. Lovallo and D. Kahneman, "Delusions of success. How optimism undermines executives' decisions," Harvard Business Review, vol. 81, no. 7, pp. 56-117, 2003.

[2] H. Shefrin, Behavioral Corporate Finance: Decisions that Create Value, McGraw-Hill, Irwin, Boston, Mass, USA, 2007.

[3] L. Ackert and R. Deaves, Behavioral Finance: Psychology, Decision Making, and Markets, South-Western Cengage Learning, Mason, Ohio, USA, 2010.

[4] U. Malmendier and G. Tate, "CEO overconfidence and corporate investment," Journal of Finance, vol. 60, no. 6, pp. 26612700, 2005.

[5] J. B. Heaton, "Managerial optimism and corporate finance," Financial Management, vol. 31, no. 2, pp. 33-45, 2002.

[6] I. Ben-David, J. R. Graham, and C. Harvey, "Managerial overconfidence and corporate policies," Working Paper, Social Science Research Network, 2007.

[7] I. Ben-David, J. R. Graham, and C. Harvey, "Managerial miscalibration," Working Paper, Social Science Research Network, 2010.

[8] M. Statman and T. Tyebjee, "Optimistic capital budgeting forecasts: an experiment," Financial Management, vol. 14, no. 3, pp. 27-33, 1985.

[9] C. Camerer and D. Lovallo, "Overconfidence and excess entry: an experimental approach," American Economic Review, vol. 89, no. 1, pp. 306-318, 1999.

[10] D. Kahnemann and A. Tversky, "Intuitive procedures, biases and corrective procedures," in Studies in Management Science: Forecasting, S. Markridakis and S. Wheelwright, Eds., vol. 12, Elsevier, North Holland, Amsterdam, The Netherlands, 1979. 


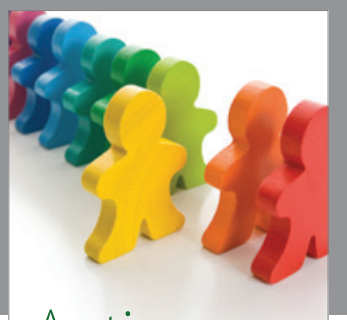

Autism

Research and Treatment
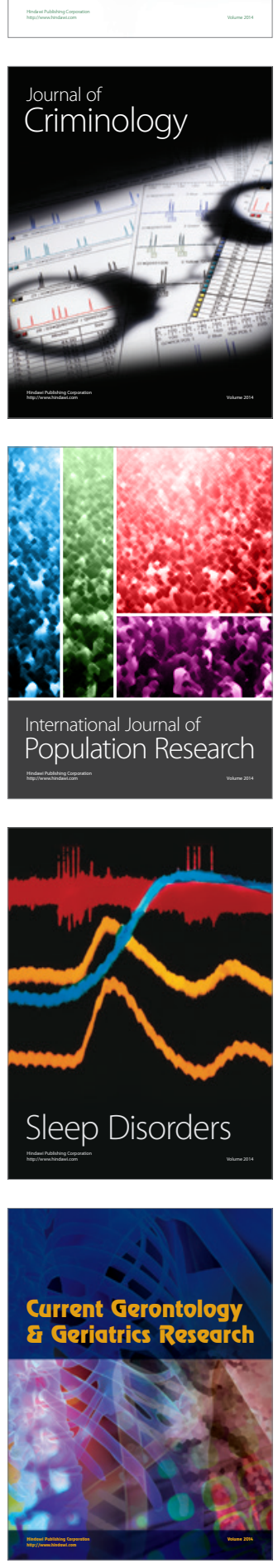
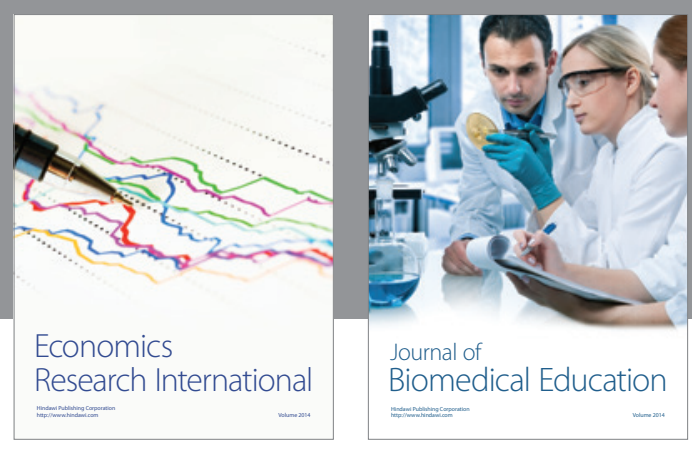

Journal of

Biomedical Education

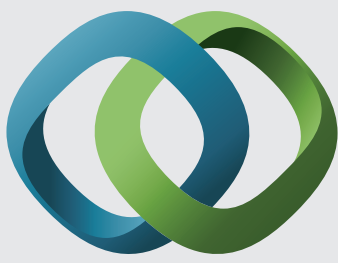

\section{Hindawi}

Submit your manuscripts at

http://www.hindawi.com
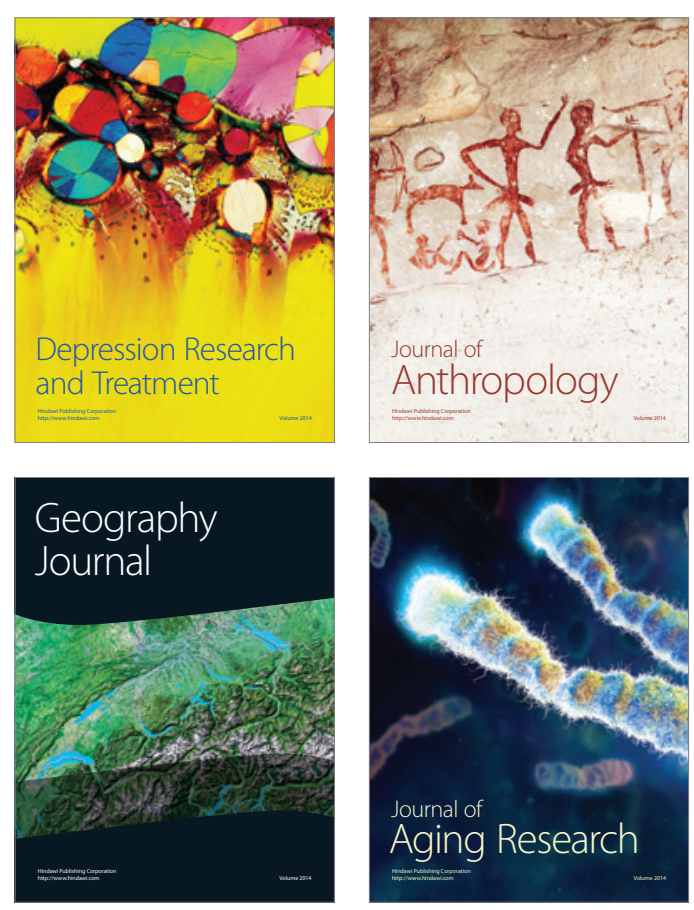

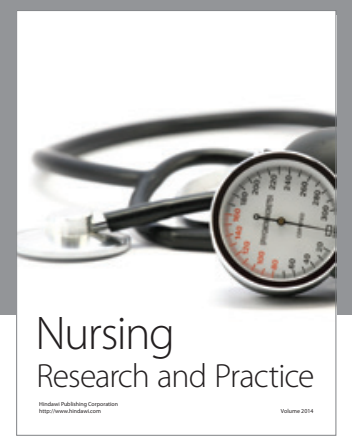

Nursing

Research and Practice

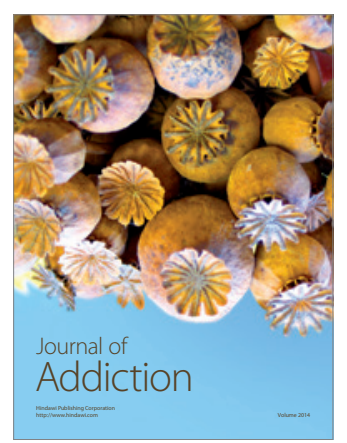

Child Development

Research

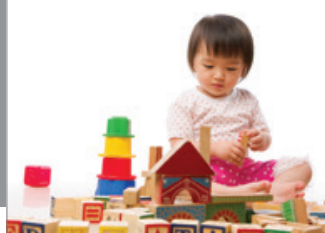

迥
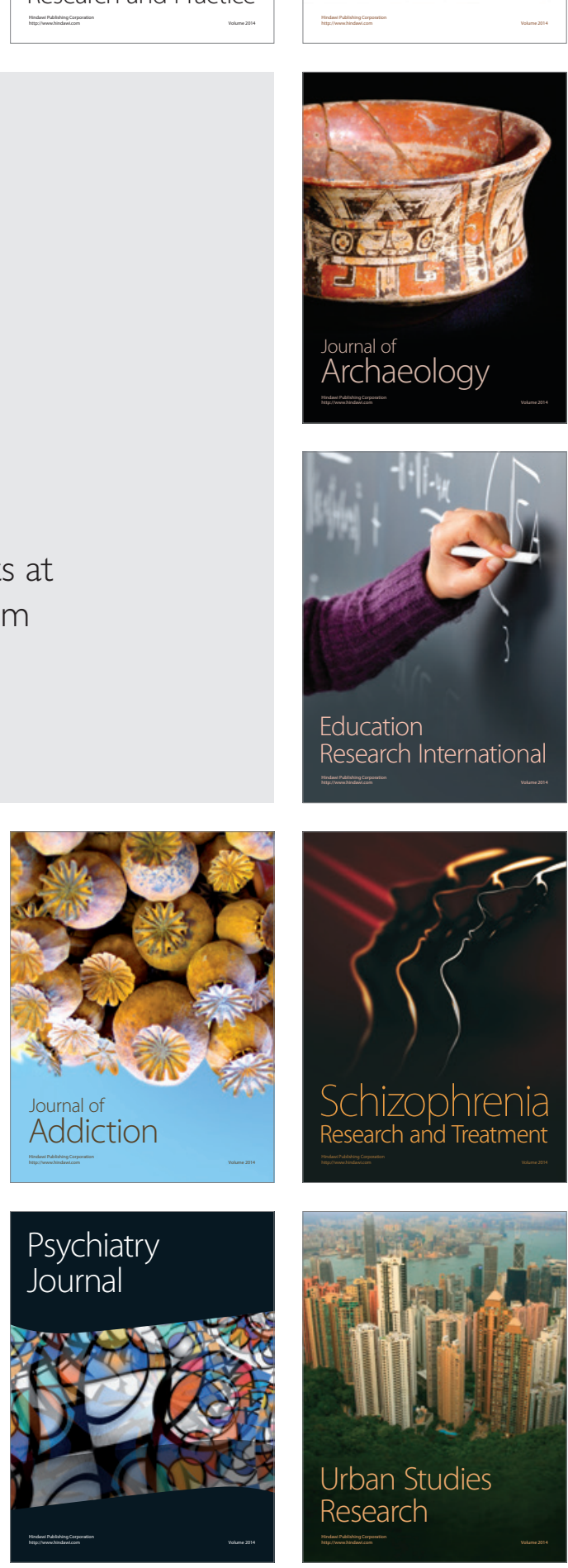